Journal of Social and Development Sciences

Vol. 3, No. 7, pp. 254-263, July 2012 (ISSN 2221-1152)

\title{
Gender, Elder Care and Care Workers in Thai Governmental Home for the Aged
}

\author{
Boontarika Narknisorn \\ Kasetsart University, Thailand \\ fsocbkn@ku.ac.th
}

\begin{abstract}
Thai government discouraged formal care. Research on care workers and care work in Thai governmental homes for the aged was limited and unvoiced. This research aimed to investigate gender, elder care and care workers in Thai governmental home for the aged by exploring (1.) gender and care workers, (2.) how elder care was performed, (3.) care workers' work condition and (4.) care workers' work satisfaction. Qualitative research was employed to understand care workers' perspectives. Research techniques were observation, focus group interview and in-depth interview with all care workers in one Thai governmental home for the aged and interview with key informants. Identifying themes and content analysis was applied. The results showed that there were more female than male care workers. Care work was socially constructed to women's roles. There was an awareness to include both genders in care work, especially demanding for same sex of care workers and older persons for personal care. Since there were high numbers of older persons, care work demanded work that is more physical. Care work was not a professional work and attracted more women who were unemployed or had low level of education. Care work was linked to unpaid or low paid work. Since Thai government discouraged formal care, more care workers experienced poor work condition and dissatisfaction due to double disadvantages of under valuation of care work and formal care. There were more dissatisfied care workers who expressed poor working condition as no advancement, inadequate salary and benefits, poor coordination among departments, conflicts among coworkers, which affected personal goals, family life and health of care workers. However, satisfied care workers expressed mental and spiritual fulfillment as love, care, attachment, life meaning and morality that could overcome negative aspects of care work. Research, policy, practical implications and recommendations were to create more awareness of gender and care work that links to care workers' work condition and satisfaction in formal care in Thailand.
\end{abstract}

Key words: Gender, elder care, care work, care workers, Thai governmental home for the aged

\section{Introduction}

Background: Thailand is one country that expresses high growth of old age population (Jitapunkul, Chayovan \& Kespichayawattana, 2002). It is predicted that in 2020, Thai old age population will reach $15 \%$ of the whole population (Jitapunkul, Chayovan \& Yodpetch, 2001). In traditional Thai culture, family was an extended type and was the main source of elder care. Thai women in the past usually stayed home to provide care for all family members and take care of household work. The quality of elder care was assumed the responsibility of family and women. However, in the present time, Thailand is experiencing many issues that are challenging family's role as the main source of elderly caretaker. Jitapunkul, Chayovan \& Kespichayawattana (2002) pointed out that Thailand is currently experiencing more nuclear families, fewer numbers of children, migration, women's employment and changes in values and lifestyle. These challenges urge Thailand to also prepare for formal elder care.

Statement of the Problem under Study: Even though there are many challenges that are affecting family as the main elderly caretaker and there are recommendations to also include formal elder care, Thai government still discourages formal care. The government reduces the numbers of the homes for the aged while there are long waiting lists of older persons, which reflect higher demand for formal care. Additionally, there is no requirement for the home registration. The homes can be provided by other private or non-governmental organizations. There is no accurate statistics of numbers of the homes and there is no quality control. Thus, the issues of elderly care work and care workers in the homes for the aged are undervalued and under investigated which is supported by Hsu et al. (2007) who pointed out that there is still the lack of research about care workers in formal care and this issue seemed to be ignored. 
Rationale: Care work is linked to unpaid or low paid work and is socially constructed to women's roles. Care work can be demanding. There are more women providing care. Since the homes for the aged are less valued, care work and work condition of care workers in this setting are also undervalued. Thus, care workers in Thai governmental homes for the aged are unvoiced and in double disadvantages.

Interest of the Research: This research focused on care workers in Thai governmental home for the aged because this group was in double disadvantages, under investigated and unvoiced. This research was interested in gender issue in care work, elder care, care workers' work condition and care workers' satisfaction.

Research Questions: Research Questions were (1.) how gender affected care workers. (2.) What were actual tasks of care work? (3.) what was care workers' work condition? In addition, (4.), how did care workers perceive their work satisfaction?

Research Objectives: The main research objective was to investigate gender, elder care and care workers in Thai governmental home for the aged. The specific objectives were (1.) to explore gender and care workers, (2.) to investigate how elderly care work was performed, (3.) to understand work condition of care workers and (4.) to explore work satisfaction of care workers.

\section{Literature Review}

Concepts of Gender and Care Work: Care is linked to gender, race and class. Care practice is a work of maintenance and continuation of the world (Tronto, 1989). Care work is a reproductive work, which is the work of maintenance, household work, the work of promoting well being or the work to preserve relationships. Since care work is usually an unpaid work, Calasanti \& Slevin (2001) pointed out that care work is not valued by society. Montgomery (1992) pointed out that many concepts contribute to an understanding of how men and women provide care. Social Learning Theory views gender as being learned. Gender learning begins since childhood as children observe and learn about gender roles from their role models (Brannon, 2002). Gender socialization is the process that boys and girls acquire their gender roles (Johnson, 1981). Walker (1992) pointed out that in order to acquire socialization, one needs to 'observe, imitate and internalize' (Brewer, 2001). Men and women have learned and acquired their gender roles, which affect their thoughts, perception and behaviors. There are different expectations regarding gender in society. As gender is a socially assigned task of men and women, care work is assigned to both genders differently. Care work is expected for women (Matthews, 1995). There are more female than male elderly caretakers (Quadagno, 2005). Women are culturally assigned for care work because of their female 'nature' (Wong, 2005). Since women's role is related to preserving relationship and family (Carroll \& Campbell, 2008), Care work for women is expanded from family role (MacRae, 1995). Walker (1992) presented psychological explanation by Chodorow (1971) and Gilligan (1982) that women express and involve more in care work because they play their roles in preserving relationship, and care work is crucial for being a woman (Brewer, 2001). Care work by women is perceived as more adequate than care work by men (Carroll \& Campbell, 2008). However, men seem to receive more admiration for their care work because it is women's work (Rose \& Bruce, 1995). Thus, male care workers are undervalued (Carroll \& Campbell, 2008). However, gender stereotype should not be applied to all men and women since each person is unique. Walker (1992) gave opinions that some women are not caring while some men are willing to care (Brewer, 2001). Brody (1981) pointed out that gender differences in care work may not be from men's lack of responsibility, but gender differences should come from how society expects roles that are suitable for men and women (Brewer, 2001). Brewer (2001) suggested that genders, public and private sectors needed to contribute to care work together.

Care Workers: In Thailand, Wongsith \& Siriboon (1999) explained the general care activities for older persons that they are cooking, doing laundry, washing dishes, cleaning, taking older persons to doctors and places, providing financial support, reading, talking to older persons, providing food and items, etc. The elder care includes social, emotional, physical and financial supports. When older persons become more dependent, the caretakers need to provide more time and energy for elder care, which includes feeding, bathing, cleaning, changing clothes, toileting, preparing medication, taking older persons to doctors etc. Many caretakers also have domestic responsibilities. The hired assistants and servants help easing the burden of caretakers. Some caretakers, who need to take care of household, family members, older persons and work, feel burdened. Care work can be demanding work and women receive more 
effects of care work since there are more women providing elder care. Brewer (2001) explained that care work could bring both negative and positive effects in some levels. In nursing home setting, Hsu et al. (2007) found that in Taiwan, care workers experienced burden demand from care work while having less time for themselves which led to stress (Hsu et al., 2007). Care work can create stress and affect health of care workers (Haley, 1997). Care work can be a routine and stressful work (Walker, 1992). Female caretakers can experience alienation, stress and financial burden (Brody, 2004). However, attitudes, values and meaning can overcome stress from care work. Wong (2005) pointed out that 'gratitude' and 'respect' can ease stress of caretakers (Wong, 2005). Walker (1992) also found that female caretakers could receive satisfaction and work values. This notion is supported by Hsu et al. (2007) who found that if care workers loved their jobs, they would have low level of stress. They also found that the income of care workers in Taiwan was less than the one in U.S.A., but income was not an important factor that affected stress (Hsu et al., 2007). Thus, mental reasons also affect stress. Other factors affect care workers' stress. "Stikvoort et al. (1994) reported that social support, growth opportunities and work pressure were related to work satisfaction, work motivation and health complaints." (Van Den Berg et al., 2006, p. 494). It was also found that 'human resource management and quality of care' influenced care workers' stress (Hsu et al., 2007). Caretakers' perception of stress depends on their views of 'physical, mental and social' results from providing care work (Izal et al., 2005). Thus, the physical, psychological and social contexts need to be explored to understand care work and work condition of care workers.

Thai Governmental Home for the Aged: In 1956, the first Thai governmental home for the aged was established (Department of Social Welfare, Thailand, 2001). The Department of Social Welfare offered the governmental homes for the aged for older persons who were 60 years old or over. They needed to have no place to live, have no one to care for or were dissatisfied to live with family (The Government of Thailand, 1995). There were 20 Thai governmental homes for the aged under management of the main government. In 2002, 13 homes were transferred to local government since Thai government discouraged formal care and expected family and community to care for older persons. Seven homes under management of the main government became the model homes for Thai residential homes if other organizations wanted to set their own homes (Office of Women and Family Affairs, 2000). Currently, there is no requirement for registration of Thai residential homes. It results in no quality control and no statistics to show the exact numbers of residential homes in Thailand. The 7 homes under management of the main government become Social Welfare Development Center for Older Persons. The duties of these centers are to encourage family and community to care for older persons and to reduce the number of older persons to live in the homes for the aged. Since Thai governmental homes for the aged are discouraged and care work is linked to low paid or unpaid work, this research focused on care work and care workers in Thai governmental home because this setting and these workers are undervalued.

\section{Methodology}

One from 7 governmental homes for the aged was purposively selected as all 7 homes were model homes and under the same standard and same management of the main government. There were 32 respondents, which composed of all care workers (12 females), 2 previous male care workers and 18 key informants from this home, local government, Ministry of Human Development and Social Security and Ministry of Health. Qualitative method was employed to understand care workers' perspectives on gender, care work, work condition and work satisfaction. Focus group technique and observation were applied for care worker respondents. In-depth interview was conducted with 2 female and 2 male care workers to explore life history and life experiences. Key informants were interviewed for issues of policy, care work and the homes for the aged. Content analysis was applied and identified themes. Data collection was conducted in Thai language and later was translated to English language.

\section{Results}

Gender and Care Workers: There were always more female than male care workers in all Thai governmental homes for the aged. Currently 12 women were care workers while there were 2 men who used to be care workers. This finding supported Matthews (1995) who pointed out that care work was expected for women which was supported by Quadagno (2005) who also mentioned that there were more female than male elderly caretakers. It could be explained that care work was women's work, which was linked to social construction of men and women's roles. Men hardly filed applications to be care 
workers in these homes. The position was not attractive; however, the finding showed an awareness of welcoming both genders in care work.

(Previous male care worker \# 1): "Men can perform caretaker's role, but most men perform tasks that need physical strengths like lifting or cleaning the building."

It reflected that care work in Thai governmental homes demanded physical work. Men could fulfill this role better than women due to their physical strength could. Care work was not attractive to men. It could be that men were not trained to care for others. Care work still attached to the roles of women. However, both male and female care workers recognized the benefit of including both genders of care workers in Thai governmental homes.

(Female care worker \# 3): "Male care workers did not feel comfortable to care for elderly women. Female care workers did not feel comfortable to care for elderly men."

It showed that if older persons and care workers were in the same gender, it would be easier and more comfortable to provide and receive care, especially close physical care. However, there were also more elderly women than elderly men in this home. There were currently 220 older persons, which composed of 70 elderly men and 150 elderly women to care for. It reflected that elder care affected the life of both elderly women and female care workers more than men.

How Elderly Care Work Was Performed: Twelve female care workers were divided into 3 groups with 4 persons in each group. One group would care for dependent older persons and 2 groups for independent one. The care workers divided the buildings where older persons were living in order to provide care. Care workers assisted older persons' physical needs, such as doing laundry by machine if older persons wanted, cleaning and organizing beds for the ones in needs, pushing the cart to bring food to eating hall, putting food in the plates for older persons, sweeping the floor, cleaning the eating hall, cleaning the building, taking older persons in needs to the hospitals, providing activities and games to older persons, talking to older persons etc. Care workers provided activities for older persons, such as exercising, praying, throwing arrows, bowling, throwing rings, providing games and taking older persons to supermarket, temples or community. Care workers would take turns each month to care for another group of older persons, which could be independent or dependent ones. Currently, there were approximately 70 dependent female older persons. All dependent older persons were always elderly women, which could reflect that elderly women lived longer than elderly men. Women had more opportunities to confront the issue of who would care for them in old ages if they did not have available family members and became dependent. The finding showed that, according to male and female care workers' perspectives, elder care in practice demanded more physical and labor work, which could be boring and was not stimulating.

(Previous male care worker \# 1):"I could care for both elderly men and women. However, male care workers usually needed to clean building and lifted heavy things. I preferred the position with lighter work with more freedom. I asked to change my position to be a gardener."

(Previous male care worker \# 2): "I used to be care worker in another home for 7 years and in this home for 7 year, but my work focused on cleaning and lifting. At that time, there were only 7-8 female care workers and 1 male care worker. There were around 10 elderly men and 180 elderly women in this home. I asked to change position to be a driver."

The finding reflected that an expectation of physical work on men was linked to the perception of men's physical strength. Care work in Thai governmental homes showed the imbalance ratio of care workers and older persons. Small number of care workers needed to care for high number of older persons; thus, care work was heavily presented as physical work. This finding also supported Wongsith \& Siriboon (1999) who explained the general care activities as physical tasks, but they also included social, emotional, physical and financial supports. It was interesting to note that male care workers asked to change position, which still involved physical work, but being a gardener or a driver gave them more freedom. They were free from care work. Male care workers did not report emotional reasons to change the type of work, but female care workers did. 
(Female care worker \# 3): "I feel so bored with the work because I hardly use knowledge that I learn from school. Care work is labor work and is not stimulating. I also get bored with coworkers."

This could be explained that since male care workers successfully changed position to be the gardener or driver, they gained more sense of independent and freedom while performing lighter work, which required less demand to care for others. The new type of work was also more suitable to men's role and could satisfy more emotional freedom and needs. In contrast, women's roles were related to emotional and social connection. Care work that lacked emotional fulfillment could affect female care workers' satisfaction. In addition, it seemed that the homes required physical work for care work. The physical type of care work was reflected in the qualifications of care workers that the applicants should not be older than 35 since elderly care work could create physical strain. There were 220 older persons for only 12 female care workers to care for, which affected physical condition of care workers. The ratio of care workers and older persons was 3:58 for independent one and 3:20 for dependent one. Thus, in this home, when care workers reached 50 , they could ask to change the work position that required lighter work. It was also noted that female care workers chose to change positions to work in women's work, such as housekeepers, cook, administrators or staffs while male care workers chose to work in men's work, such as drivers or gardeners. Both male and female care workers also tried to perform emotional and social supports by listening and communicating to older persons. They ensured older persons' needs for assistance by talking. However, with high number of older persons and small number of care workers, the physical work took care worker's time and energy from emotional and social care, but care workers still performed these tasks. There were incidents that care workers needed to cope and find solutions for conflicts among older persons. Time and energy for emotional care were also put on problematic cases instead of investing for all older persons.

(Female care worker \# 4): "More elderly women had conflicts than elderly men. The younger ones had more conflicts than the older ones."

Living in the governmental home meant that older persons needed to live with other older persons with various personalities. They needed to adjust to the home and other people. The finding showed that younger elderly women had more conflicts among one another than the older ones and another gender. It could be explained that women was socially trained to focus more on emotion, relationship and sensitive issues which could make some elderly women become annoyed by others' behaviors. Additionally, elderly women in older ages would gain control that is more emotional or confronted more physical deterioration, which prevented them from conflicts. Some older persons woke up early and needed assistance. Some older persons did not express nice behaviors. Care workers needed to adjust to older persons' needs and personalities. In addition, with the limited governmental budget and limited staffs, care workers needed to perform other types of work. They needed to greet the visitors who visited the home and go to communities every month to assist families to care for older persons in the communities. Thus, care workers in Thai governmental home did not limit their work to just care work, but they needed to perform various tasks to help the home function.

\section{Care Workers' Work Condition}

According to focus group interview with care workers and interview with key informants, care workers in Thai governmental homes for the aged needed to be trained and practiced to work with older persons; however, many applicants denied working with dependent older persons because it required body cleaning.

(Previous male care worker \# 1): "Care workers need to complete grade 6 or 12. They need to be trained and try to care for older persons. Most applicants deny working with dependent ones. They do not want to clean other people's bodies. We need caring people. People with high education will not do this type of work."

Care work was more than a physical care work. However, with small number of care workers, care workers were overwhelmed with physical care. Physical work did not require much knowledge and high education. This finding supported Calasanti \& Slevin (2001) who pointed out that care work was not valued by society. In addition, it reflected the under valuation of care work which could be the reason why care work was not registered or licensed and developed to be a professional work with high salary and benefits. According to this research study, there were 3 types of care workers: (1.) Governmental 
employees: Governmental employees received salary and received benefits for themselves and family members. Their salary could increase. They would receive governmental retirement fund. They could be in executive positions. (2.) Regular employees: They received the same benefits as governmental employees, but they could not earn executive positions. (3.) Temporary employees: They received low salary. They did not receive benefits. Temporary workers provided the same work as regular workers and governmental employees, but salary and benefits were less. From 12 female care workers, there was only 1 governmental employee, 2 regular employees and 9 temporary employees while 2 previous male care workers were both regular employees. Now, there was only the position for temporary employee. This could reflect government's budget cut. Care workers who worked with dependent older persons would receive the extra money of $750 \mathrm{baht} /$ month (approximately $31 \mathrm{baht}=1$ U.S. dollar). The work time was 8 a.m. - 5 p.m. except the ones who had duties to stay overnight in older persons' buildings. Care workers needed to take turn to have 2-day holidays, which might not be the weekend. Care workers had their rooms and could stay with family in this home. They also needed to pay for their own electrical bill. Care workers needed to have income reduction to pay for social insurance. They received some free meals if there was some food left in the pots after serving all older persons. This also reflected that care workers in Thai governmental home did not receive good benefits and their well-being was undervalued. However, care workers still received some training from the home.

Thai governmental discouraged formal care, but encouraged family and community cares. Thai government changed 7 governmental homes for the age, including this home, to be Social Welfare Development Centers for Older Persons. As a result, this home did not have plans to accept more cases. However, in practice, the home still accepted new cases because the homes for the aged were still in demand. The role of being Social Welfare Development Center for Older Persons made staffs and care workers go out to the communities to train volunteers to assist families to provide family care. Staffs would transfer knowledge to older persons and families in communities. Some care workers needed to also perform this task due to limited staffs. This project received budget from the government. The home started this project for 7 groups. With various tasks care workers in this governmental home for the aged were expected to perform combining with high numbers of older persons to be cared, low salary and small benefits, care workers agreed with poor work condition.

(Previous male care worker \# 1): "In this home, the ratio of care workers per older persons was 3:58 for independent ones and 3:20 for dependent ones. Care workers do not earn enough money, welfare and benefits."

It reflected the attachment of care work with reproductive work, unpaid work or low paid work. Care workers were not guaranteed with good quality of life. They wanted more money, more benefits and better positions. They wanted benefits for their children and family. They wanted educational funds for their children. The coordination among departments was poor. There was no strict and clear rule to follow. There were conflicts among coworkers. Care workers in each group needed to take turn for 2 holidays each week, which might not be the weekend. This made it harder for care workers to find extra job. Care workers hoped for more number of caretakers, which included men. Since care workers in this home carried heavy demand for care work, they hoped for family and community to play their roles of elder care.

Work Satisfaction of Care Workers: 5 female care workers who were satisfied with their work while there were 7 females and 2 males were dissatisfied.

Satisfied Care Workers: Five females expressed their satisfaction with mental reasons. All of satisfied care workers were females. They wanted to provide care work because of love, care and attachment to care work and older persons and because of life meaning.

(Female care worker \# 1): "I love my work. I feel happy and put my heart on my work and older persons."

(Female care worker \# 2): "I have empathy for older persons. Elderly care work makes me become more patient, kind, loving, giving and forgiving. I become a better person. I learn from others' life experiences. I feel happy to do this work. Caring for others is doing good things. It brings goodness to my life. I have a very good husband and 2 obedient sons. I have a happy family life." 
The sense of work satisfaction was linked to these care workers' perception of meaning and morality. Care work could be perceived as the work of giving and preserving other people is well being which, in turn, provided the sense of meaning and fulfillment to care workers. Positive care also required positive regards and caring personalities, which enhanced care workers' self-reflection and personal growth. Caring was also associated with goodness and good outcomes to be appreciated. Thus, care workers who felt satisfied with their care work recognized their work values. They perceived that they were receiving mental and spiritual rewards, which could overcome other negative aspects of care work here.

Dissatisfied Care Workers: However, there were more male than female care workers who did not feel satisfy with their work. Their reasons were low income and benefits, conflict with family life and health problems.

\section{b. 1. Low Income and Benefits}

(Female care worker \# 7): I want more money. I have worked here for 5-6 years, but the salary never increases. I want more employees to help us and want better benefits. I also need to pay for social insurance each month."

The income and benefits were important for living. The lack of increasing salary and adequate benefits reflected limited governmental funds and the devaluation of care workers' life condition in formal care. It also reflected that care work was undervalued and was linked to unpaid or low paid work. Since both formal care and care work were not well valued, care workers in this home were also undervalued and were receiving double disadvantages.

\section{b. 2. Conflict with Family Life}

(Female care worker \# 8): "I was unemployed and need money. My youngest daughter is very sick. I need a job and money. I do not want to work, but I need to. I want to care for my daughter. I still do not earn enough money."

Since care work demanded more labor work and required low level of education, care work also attracted some unemployed persons who were experiencing financial difficulties. However, this reason for being care workers would be an obstacle to provide quality care. The unwillingness to work because of conflict with family life also caused dissatisfaction. It reflected that financial need and the needs to support family caused some care workers to choose this choice. It was the necessity to work, not the willingness to work.

(Female care worker \# 10): "We all have 2 days off each week. We need to take turn in our group. I may not have holidays during the weekend to spend time with my family."

Care work in this home required 24-hour available care and care workers needed to take turn to stay overnight in older persons' buildings. Limited number of care workers, limited holidays and irregular holidays could affect care workers' personal life.

b. 3. Health Problems: Physical burden and complains reflected care workers' health problems since both male and female care workers needed to perform physical tasks every working days.

(Previous male care worker \# 1): "I applied to be the care worker here because I could do the work. I have empathy for older persons. I cared for both elderly men and women for many years and felt fine. However, I also needed to clean the buildings and lift heavy things because I was the only male caretaker at that time. It affected my body. I asked for lighter position. I am a gardener now. I am happier and have more freedom. I prefer being a gardener."

(Female care worker \# 3): "When I started working here, there were around 100 older persons, 4 female and 1 male care workers. I want to work in personal department of some companies. I want to quit my job. If I can quit today, I will. I feel unhappy with my work. I am having allergy for dirt. My eyes are teary, swollen and red. I have runny nose. Cleaning buildings, beds and clothes worsens my allergy symptoms. I need to pay $690 \mathrm{baht} / \mathrm{month}$ for doctor. I cannot take sick leave too often because it will be looked as though I am taking 

old now."

In Thailand, workplaces usually set gender and ages of applicants to be recruited for employees. In general, the workplaces indicated and required young people. Older ages could be obstacles to find new jobs. Since care workers' tasks required low level of education and labor work, it could affect physical health or contributed to accumulative future health problems. More care workers felt dissatisfied with their work. Their dissatisfaction linked to the types of care work being performed, an inadequate salary and benefits, the welfare of their families, the quality of their personal life, the unwillingness to work, poor work condition and health problems.

Discussion: Thai governmental homes for the aged were undervalued. It was reflected on a budget cut, a reduction of numbers of the homes, no home registration and the policy that tried to push elder care responsibility to family and community. Care work was also undervalued because care workers expressed poor working condition and care work attracted unemployed and low educated workers. These 2 reasons showed no supports to transform care work to professional work. Care work was linked to unpaid or low paid work. Since Thai governmental home for the aged was undervalued and care work was undervalued, care workers in Thai governmental home for the aged were in double disadvantages. There were more female than male care workers, which were supported by Quadagno (2005). It reflected that women received more effects of care work than men. This could be explained that women were socially assigned to provide care. There were more women applying for care work position. Gender also affected career choice. Men requested for changing position to be drivers or gardeners while women requested to be cook or administrators. Even though there was an awareness of care workers to include both genders in care work, men's care work was linked to men's physical strengths and labor work. Both male and female care workers tried to provide physical, social and emotional supports. However, with high number of older persons to be cared, care work in this setting was pushed for physical demand. Thus, both factors of gender and work condition affected the type of care being provided. An awareness of including both genders in care work reflected on personal care. Both male and female care workers expressed more comfortable feelings to care for older persons in same sex. This finding implied the importance of matching gender of care workers and older persons to provide quality care.

Brewer (2001) explained that care work can bring both negative and positive effects in some levels. This finding expressed more care workers' dissatisfaction and poor working condition as no advancement, inadequate salary and benefits, high demand for care work, poor coordination among departments and conflicts among coworkers. Poor working condition affected care workers' family life, health and other personal goals. This finding was supported by many researchers who found that less time for oneself (Hsu et al., 2007), health problems (Haley, 1997) and routine work (Walker, 1992) could bring stress to care workers. However, Hsu et al. (2007) found that, in Taiwan, care workers' income was not an important factor that affected stress. In this finding, income and benefits were crucial issues for stress because they were not adequate for living. This might be explained by different standard of living in Taiwan and Thailand. Care work also expressed positive sides. Satisfied care workers expressed their reasons of love, care, attachment, life meaning, morality, and personal growth, mental and spiritual rewards that overcame negative aspects. This finding was supported by many scholars who found that 'gratitude' and 'respect' (Wong, 2005), work values (Walker, 1992) and love (Hsu et al., 2007) could ease stress. Care work should be valued and attract care workers who possessed these qualities. Policy needed to recognize that care work was an important work to preserve others' well being. Care workers should receive adequate benefits and care work should become a professional work. This finding supported past research, which showed that "social support, growth opportunities and work pressure were related to work satisfaction, work motivation and health complaints." (Stikvoort et al., 1994 in Van Den Berg et al., 2006, p. 494). 'Human resource management and quality of care' influenced care workers' stress (Hsu et al., 2007). Thus, Caretakers' perception of stress depends on their views of 'physical, mental and social' results from providing care work (Izal et al., 2005).

\section{Conclusion}

There were more female than male care workers since gender was linked to care work. Women were socially assigned to provide more elder care. As care work in Thai governmental home for the aged was discouraged, there was small number of care workers to provide care for high number of older persons. 
Elder care in the home for the aged demanded physical work, and could affect physical strain of care workers. The work condition was poor, but work satisfaction depended on care workers' values of work, meaning, salary, benefit, family life and health. Care work was attached to unpaid or low paid work and the task of women. Thai government devalued formal care. These double disadvantages affected female care workers' elder care, work condition and work satisfaction in Thai governmental home for the aged, which needed to be voiced.

Recommendation: Since the governmental homes for the aged were still necessary and were still in demand for older persons in needs, the concept of elder care, actual care work, care workers' work condition and care workers' work satisfaction needed to be improved for higher quality. The recommendations were: (1.) including both men and women for care workers, (2.) increasing number of care workers in order to have more time and energy to provide emotional and social supports, (3.) increasing salary, benefits, holidays, financial security and career advancement for care workers, (4.) having licensing or registration for residential care and homes for the aged in Thailand for quality control and statistical benefits, (5.) having licensing or registration for care workers as one important professional.

\section{References}

Brannon, L. (2002). Gender Psychological Perspectives ( $3^{\text {rd }}$ Ed), Massachusetts: Allyn and Bacon.

Brewer, L. (2001). Gender Socialization and the Cultural Construction of Elder Caregivers. Journal of Aging Studies, 15(3), 217-235.

Brody, E. (1981). Women in the Middle and Family Help to Older People, in Brewer, L. (2001). Gender Socialization and the Cultural Construction of Elder Caregivers. Journal of Aging Studies, 15(3), 217-235.

Brody, E. M. (2004). Women in the Middle: Their Parent Care Years (2 ${ }^{\text {nd }}$ Ed), in Wong, O. M. H. (2005). Gender and Intimate Care giving for the Elderly in Hong Kong. Journal of Aging Studies, 19(3), 375-391.

Calasanti, T. M. \& Slevin, K. F. (2001). Gender, Social Inequalities and Aging, in Carroll, M. \& Campbell, L. (2008). Who Now Reads Parsons and Bales: Casting a Critical Eye on the Gendered Styles of Care giving Literature? Journal of Aging Studies, 22(1), 24-31.

Carroll, M. \& Campbell, L. (2008). Who Now Reads Parsons and Bales: Casting a Critical Eye on the Gendered Styles of Care giving Literature? Journal of Aging Studies, 22(1), 24-31.

Chodorow, N. (1971). Being and Doing: A Cross-Cultural Examination of the Socialization of Males and Females, in Gomick, V. \& Moran, B. (Eds.). (1971). Woman in Sexist Society, in Brewer, L. (2001). Gender Socialization and the Cultural Construction of Elder Caregivers. Journal of Aging Studies, 15(3), 217-235.

Connidis, I. A. (2010). Family Ties and Aging (2 $2^{\text {nd }}$ Ed), California: Pine Forge Press.

Department of Social Welfare, Thailand. (2001). A Social Welfare for the Aged, in Jitapunkul, S. N. Chayovan, N. \& Kespichayawattana, J. (2002). Ch. 6 National Policies on Ageing and Long-Term Care Provision for Older Persons in Thailand. http://www.idrc.ca/en/ev-28478-201-1DO_TOPIC.html.

Gilligan, C. (1982). In a Different Voice, in Brewer, L. (2001). Gender Socialization and the Cultural Construction of Elder Caregivers. Journal of Aging Studies, 15(3), 217-235.

Haley, W. (1997). The Family Caregivers Role in Alzheimer's Disease, in Brewer, L. (2001). Gender Socialization and the Cultural Construction of Elder Caregivers. Journal of Aging Studies, 15(3), 217-235.

Held, V. (1995). Justice and Care: Essential Readings in Feminists Ethics, U. S. A.: West view Press.

Hsu, H. C., Kung, Y. W., Huang, H. C., Ho, P. Y., Lin, Y. Y. \& Chen, W. S. (2007). Work Stress among Nursing Home Care Attendants in Taiwan: A Questionnaire Survey. International Journal of Nursing Studies, 44, 736-746.

Izal, M., Montorio, I., Marquez, M. \& Losada, A. (2005). Caregivers Expectations and Care Receivers Competence Lawton's Ecological Model of Adaptation and Aging Revisited. Archives of Gerontology and Geriatrics, 41(2), 129-140.

Jitapunkul, S., Chayovan, N. \& Kespichayawattana, J. (2002). Ch. 6 National Policies on Ageing and LongTerm Care Provision for Older Persons in Thailand. http://www.idrc.ca/en/ev-28478-201-1DO_TOPIC.html. 
Jittapunkul, S., Chayovan, N. \& Yodpetch, S. (2001). Elderly in Thailand: An Extensive Review of Current Data and Situation, and Policy and Research Suggestions, in Jitapunkul, S. N. Chayovan, N. \& Kespichayawattana, J. (2002). Ch. 6 National Policies on Ageing and Long-Term Care Provision for Older Persons in Thailand. http://www.idrc.ca/en/ev-28478-201-1-DO_TOPIC.html.

Johnson, R. (1981). The Black Family and Black Community Development, in Brewer, L. (2001). Gender Socialization and the Cultural Construction of Elder Caregivers. Journal of Aging Studies, 15(3), 217-235.

MacRae, H. M. (1995). Women and Caring: Constructing Self through Others, in Carroll, M. \& Campbell, L. (2008). Who Now Reads Parsons and Bales: Casting a Critical Eye on the Gendered Styles of Care giving Literature? Journal of Aging Studies, 22(1), 24-31.

Matthews, S. H. (1995). Gender and the Division of Filial Responsibility between Lone Sisters and the Brothers, in Connidis, I. A. (2010). Family Ties and Aging ( $2^{\text {nd }}$ ed), California: Pine Forge Press.

Montgomery, R. (1992). Gender Differences in Patterns of Child-Parent Care giving Relationships in Dwyer, J. and Coward, R. (Eds.). (1992). Gender, Families, and Elder Care, in Brewer, L. (2001). Gender Socialization and the Cultural Construction of Elder Caregivers. Journal of Aging Studies, 15(3), 217-235.

Office of Women and Family Affairs, Ministry of Social and Human Security Development. (2000). Report on Women Status, Bangkok, Thailand: Kurusapa Printing.

Quadagno, J. (2005). Aging and the Life Course: An Introduction to Social Gerontology, Boston: McGraw Hill.

Rose, H. \& Bruce, E. (1995). Mutual Care but Differential Esteem: Caring between Older Couples, in Arber, S. \& Ginn, J. (Eds.). Connecting Gender and Ageing: A Sociological Approach, in Carroll, M. \& Campbell, L. (2008). Who Now Reads Parsons and Bales: Casting a Critical Eye on the Gendered Styles of Care giving Literature? Journal of Aging Studies, 22(1), 24-31.

Stikvoort, R., Landeweerd, A. \& De Jonge, J. (1994). Work and Worker Reactions in Homes for the Aged, in Van Den Berg, T. I. J., Landeweerd, J. A., Tummers, G. E. R. \& Van Merode, G. G. (2006). A Comparative Study of Organizational Characteristics, Work Characteristics and Nurses Psychological Work Reactions in a Hospital and Nursing Home Setting. International Journal of Nursing Studies, 43, 491-505.

Tronto, J. (1989). Women and Caring: What Can Feminism Learn about Morality from Caring, in Held, V. (Ed.) (1995). Justice and Care: Essential Readings in Feminists Ethics, U.S.A.: Westview Press.

The Government of Thailand. (1995). Thailand National Report, in World Summit for_Social Development, 6-12 March, Copenhagen, Denmark.

Van Den Berg, T. I. J., Landeweerd, J. A., Tummers, G. E. R. \& Van Merode, G. G. (2006). A Comparative Study of Organizational Characteristics, Work Characteristics and Nurses' Psychological Work Reactions in a Hospital and Nursing Home Setting. International Journal of Nursing Studies, 43, 491-505.

Walker, A. (1992). Conceptual Perspectives on Gender and Family Care giving, in Dwyer, J. and Coward, R. (Eds.). (1992). Gender, Families, and Elder Care, in Brewer, L. (2001). Gender Socialization and the Cultural Construction of Elder Caregivers. Journal of Aging Studies, 15(3), 217-235.

Wong, O. M. H. (2005). Gender and Intimate Care giving for the Elderly in Hong Kong. Journal of Aging Studies, 19(3), 375-391.

Wongsith, M. \& Siriboon, S. (1999). Family and the Elderly: Case Study of Bangkok and Phra Nakorn Sri Ayutthaya, CPS Publication, No. 273/99, January, College of Population Studies, Chulalongkorn University, Thailand.

Acknowledgement: I would like to thank all respondents and key informants for valuable information. 